\title{
Antimicrobial and antiviral sesquiterpenoids from sponge-associated fungus, Aspergillus sydowii ZSDS1-F6
}

\author{
Jun-Feng Wang ${ }^{1,4}$, Xiu-Ping Lin ${ }^{1,4}$, Chun Qin ${ }^{1}$, Sheng-Rong Liao ${ }^{1}$, Jun-Ting Wan ${ }^{2}$, Tian-Yu Zhang ${ }^{2}$, Juan Liu ${ }^{1}$, \\ Mangaladoss Fredimoses ${ }^{1}$, Hao $\mathrm{Chen}^{3}$, Bin Yang ${ }^{1}$, Xue-Feng Zhou ${ }^{1}$, Xian-Wen Yang ${ }^{1}$, Zheng-Chao $\mathrm{Tu}^{2}$ \\ and Yong-Hong Liu ${ }^{1}$
}

The Journal of Antibiotics (2014) 67, 581-583; doi:10.1038/ja.2014.39; published online 16 April 2014

Infectious diseases have seriously threatened the human health worldwide. ${ }^{1}$ One of the more alarming recent trends in infectious diseases has been the increasing frequency of antimicrobial resistance among microbial pathogens. Numerous classes of antimicrobial agents have become less effective as a result of the emergence of antimicrobial resistance due to overuse or misuse of existing antimicrobial drugs and have become a global public health problem. ${ }^{2}$ Thus, it is extremely urgent to develop new antibiotics with novel structures and significant bioactivities.

Marine microorganisms are recognized as important sources of pharmacologically active metabolites. ${ }^{3}$ In particular, a growing number of marine-derived fungi have been reported to produce novel bioactive secondary metabolites. ${ }^{4,5}$ As part of our ongoing efforts to discover structurally novel and bioactive natural compounds from spongeassociated fungi, fungal strain ZSDS1-F6, identified as Aspergillus sydowii, was isolated from an unidentified marine sponge, collected from the Xisha Islands of China. The genus Aspergillus (Moniliaceae), widely found in nature with over 180 species, has attracted considerable attention as a rich source of alkaloids, terpenoids, xanthones, polyketides and etc. These compounds exhibited antifungal, antibacterial, anti-HIV and cytotoxic activities. ${ }^{6-8}$

A. sydowii have been reported mainly from marine sources and produce unique and biologically active secondary metabolites. ${ }^{9-12}$ When fermented in an oligotrophic medium, the EtOAc extract of A. sydowii ZSDS1-F6 showed significant antimicrobial activity against Klebsiella pneumonia and Aeromonas hydrophila, and richer chemodiversity than those from the nutritive media. Chemical studies of this extract resulted in the isolation and identification of one new bisabolane-type sesquiterpenoid, aspergillusene C (1), together with 11 known compounds (Figure 1), 7-deoxy-7,14-didehydrosydonol
(2) ${ }^{9} \quad$ aspergillusene A (3), ${ }^{11} \quad(Z)-5$-(Hydroxymenthyl)-2- $\left(6^{\prime}\right)$ methylhept-2'-en-2'-yl)-phenol (4), ${ }^{13}$ anhydrowaraterpol (5), ${ }^{14}$ cyclowaraterpol A (6), ${ }^{14}$ sydonic acid $(7),{ }^{15}(S)-(+)$-dehydrosydonic acid $(8),{ }^{16}(7 S, 11 S)-(+)$-12-acetoxysydonic acid (9), ${ }^{16}$ diorcinol (10), ${ }^{17}$ cordyol C (11) ${ }^{18}$ and cyclo-(L-Trp- $L$-Phe) (12). ${ }^{19}$ Their structures were elucidated using extensive spectroscopic techniques. The isolated compounds were evaluated for their antimicrobial, antiviral $\left(\mathrm{H}_{3} \mathrm{~N}_{2}\right)$, antituberculosis and cytotoxic activities, respectively. We present herein the fermentation, isolation, structure elucidation (Supplementary Figures S1-S7), antimicrobial and antiviral activities of compounds 1-12.

Compound (1) was obtained as a colorless gum, and the molecular formula $\mathrm{C}_{15} \mathrm{H}_{20} \mathrm{O}_{4}$ was established by HRESIMS data. The UV spectrum displayed absorption bands at 205 and $253 \mathrm{~nm}$, characteristic of an aromatic chromophore. The IR spectrum exhibited absorption bands for hydroxy and double-bond functionalities at 3375 and $1686 \mathrm{~cm}^{-1}$, respectively (Supplementary Figure S8). The ${ }^{1} \mathrm{H}$ NMR spectrum (Table 1) showed characteristic signals for three aromatic protons of a 1,2,4-trisubstituted benzene $\left(\delta_{\mathrm{H}} 7.46(\mathrm{~d}, J=8.0\right.$ $\mathrm{Hz}), 7.44(\mathrm{~s})$ and $7.16(\mathrm{~d}, J=8.0 \mathrm{~Hz})$ ), one olefinic proton of a trisubstituted double-bond $\left(\delta_{\mathrm{H}} 5.63, \mathrm{td}, J=7.0\right.$ and $\left.1.2 \mathrm{~Hz}\right)$ and three methyl groups $\left(\delta_{\mathrm{H}} 2.03(\mathrm{~s}), 0.9942(\mathrm{~d}, J=6.8 \mathrm{~Hz})\right.$ and 0.9918 $(\mathrm{d}, J=6.7 \mathrm{~Hz}))$. Three aromatic protons resonating at $\delta_{\mathrm{H}} 7.46,7.44$ and 7.16 were assigned as $\mathrm{H}-4, \mathrm{H}-6$ and $\mathrm{H}-3$, respectively, on the basis of their multiplicities, coupling constants and $3 J \mathrm{HMBC}$ correlations: $\mathrm{H}-3 / \mathrm{C}-1\left(\delta_{\mathrm{C}} 155.3\right)$ and $\mathrm{C}-5\left(\delta_{\mathrm{C}} 132.3\right) ; \mathrm{H}-4 / \mathrm{C}-2\left(\delta_{\mathrm{C}} 139.1\right)$ and $\mathrm{C}-6$ $\left(\delta_{\mathrm{C}} 117.6\right) ; \mathrm{H}-6 / \mathrm{C}-2$ and C-4 $\left(\delta_{\mathrm{C}} 122.1\right)$ (Figure 2$)$. The key HMBC correlations between $\mathrm{H}-4$ and $\mathrm{C}-15\left(\delta_{\mathrm{C}} 170.9\right)$, and H-6 and C-15 indicated that the carboxyl unit was located at C-5 of the benzene ring. The cross-peaks between $\mathrm{H}_{2}-9\left(\delta_{\mathrm{H}} 2.42,2.33\right)$ and $\mathrm{H}-8\left(\delta_{\mathrm{H}}\right.$

${ }^{1}$ CAS Key Laboratory of Tropical Marine Bio-Resources and Ecology, South China Sea Institute of Oceanology, Chinese Academy of Sciences, Guangzhou, China; ${ }^{2}$ Guangzhou Institutes of Biomedicine and Health, Chinese Academy of Sciences, Guangzhou, China and ${ }^{3}$ Key Laboratory of Marine Bioactive Substances, First Institute of Oceanography, State Oceanic Administration Republic of China, Qingdao, China

${ }^{4}$ The first two authors contributed equally to this work.

Correspondence: Dr Z-C Tu, Guangzhou Institutes of Biomedicine and Health, Chinese Academy of Sciences, Guangzhou 510530, China.

E-mail: tu_zhengchao@gibh.ac.cn

or Dr Y-H Liu, CAS Key Laboratory of Tropical Marine Bio-Resources and Ecology, South China Sea Institute of Oceanology, Chinese Academy of Sciences, Guangzhou 510301, China.

E-mail: yonghongliu@scsio.ac.cn

Received 13 September 2013; revised 21 January 2014; accepted 2 February 2014; published online 16 April 2014 
<smiles>[R][R]c1ccc(/C(C)=C/CC([R2])C(C)C)c(O)c1</smiles>

1: $\mathrm{R}_{1}=\mathrm{COOH}, \mathrm{R}_{2}=\mathrm{OH}$ 3: $\mathrm{R}_{1}=\mathrm{CH}_{2} \mathrm{OH}, \mathrm{R}_{2}=\mathrm{H}$

HOOC<smiles>[R]C(C)CCC[C@@](C)(O)c1ccc(I)cc1O</smiles>

7: $\mathrm{R}=\mathrm{CH}_{3}$ 9: $\mathrm{R}=\mathrm{CH}_{2} \mathrm{OCOCH}_{3}$<smiles>C=C(CCCC(C)C)c1ccc(CO)cc1O</smiles>

2<smiles>C=C(C)CCC[C@](C)(O)c1ccc(C(=O)O)cc1O</smiles><smiles>[R]C(C)CC/C=C(/C)c1ccc(CO)cc1O</smiles>

4: $\mathrm{R}=\mathrm{CH}_{3}$ 5: $\mathrm{R}=\mathrm{CH}_{2} \mathrm{OH}$<smiles>CC1CCC[C@](C)(c2ccc(CO)cc2O)OC1</smiles>

6<smiles>[R]c1c(O)cc(C)cc1Oc1cc(C)cc(O)c1</smiles>

12

Figure 1 Chemical structures of compounds 1-12. A full color version of this figure is available at The Journal of Antibiotics journal online.

5.63)/H-10 $\left(\delta_{\mathrm{H}} 3.47\right), \mathrm{H}-10$ and $\mathrm{H}_{2}-9 / \mathrm{H}-11\left(\delta_{\mathrm{H}} 1.75\right)$, and $\mathrm{H}-11$ and $\mathrm{H}-10 / \mathrm{H}_{3}-12\left(\delta_{\mathrm{H}} 0.9942\right) / \mathrm{H}_{3}-13\left(\delta_{\mathrm{H}} 0.9918\right)$ were observed in the ${ }^{1} \mathrm{H}-{ }^{1} \mathrm{H}$ COSY spectrum (Figure 2). It allowed establishment of the isopentane unit, located at a double-bond group, which was further supported by key $\mathrm{HMBC}$ correlations from $\mathrm{H}_{2}-9$ to $\mathrm{C}-7$ ( $\left.\delta_{\mathrm{C}} 136.7\right)$ and $\mathrm{H}-10$ to $\mathrm{C}-8\left(\delta_{\mathrm{C}} 128.8\right)$. The key HMBC correlations between $\mathrm{H}-3$ and $\mathrm{C}-7, \mathrm{H}_{3}-14\left(\delta_{\mathrm{H}} 2.03\right)$ and $\mathrm{C}-2 / \mathrm{C}-7 / \mathrm{C}-8$, and $\mathrm{H}-8\left(\delta_{\mathrm{H}} 5.63\right)$ and $\mathrm{C}-2$ indicated that the olefinic carbon $\mathrm{C}-7$ was directly connected to the 1,2,4-trisubstituted benzene ring. The substituent at $\mathrm{C}-1$ of the 1,2,4-trisubstituted benzene ring and $\mathrm{C}-10\left(\delta_{\mathrm{C}} 77.5\right)$ of the isopentane unit were identified as a hydroxy group, respectively, according to the chemical shift of C-1 and C-10. Furthermore, the existence of the two hydroxy groups also could be suggested on the basis of the HRESIMS data. In addition, the key NOESY correlation between $\mathrm{H}_{3}-14$ and $\mathrm{H}_{2}-9$ clearly indicated an $E$-configuration of $\Delta 7$ double bold (Figure 2). In fact, the modified Mosher's method was tried to determine the absolute configuration of C-10 in 1; unfortunately, the reaction failed. Owing to the paucity of material, the single crystal of $\mathbf{1}$ was also not obtained through many attempts with different solvents. Consequently, compound 1 , which is named aspergillusene $C$, was identified as (E)-3-hydroxy-4-(5-hydroxy-6-methylhept-2-en-2-yl)-benzoic acid.

The isolated compounds were evaluated for their antimicrobial and antiviral $\left(\mathrm{H}_{3} \mathrm{~N}_{2}\right)$ activities. Among them, compounds 3, 4 and 10 showed modest antimicrobial activities against $K$. pneumonia with MIC values of $21.4,10.7$ and $21.7 \mu \mathrm{M}$, respectively, and compound 3 exhibited the moderate antimicrobial activity against A. hydrophila with MIC value of $4.3 \mu \mathrm{M}$, while compound 7 showed modest antimicrobial activity against $E$. faecalis with MIC value of $18.8 \mu \mathrm{M}$. In addition, compounds 4, 10 and 11 displayed weak anti- $\mathrm{H}_{3} \mathrm{~N}_{2}$ activity with $\mathrm{IC}_{50}$ values of $57.4,66.5$ and $78.5 \mu \mathrm{M}$, respectively, while none of the compounds exhibited cytotoxic effects on the tested cancer cell lines $\left(\mathrm{IC}_{50}>100 \mu \mathrm{M}\right)$ or any additional antituberculosis activities $(\mathrm{MIC}>100 \mu \mathrm{M})$.

\section{MATERIALS AND METHODS}

\section{General experimental procedures}

Optical rotations were measured with a PerkineElmer 341 polarimeter. UV spectra were recorded on a Shimadzu UV-2401PC spectrometer. IR spectra were measured on JASCO FT/IR-480 plus spectrometer with $\mathrm{KBr}$ pellets. ${ }^{1} \mathrm{H},{ }^{13} \mathrm{C}$ NMR, DEPT and 2D-NMR spectra were recorded on the Bruker DRX-500 spectrometer using TMS as internal standard, and chemical shifts were recorded as $\delta$-values. HRESIMS (including ESIMS) spectra were recorded

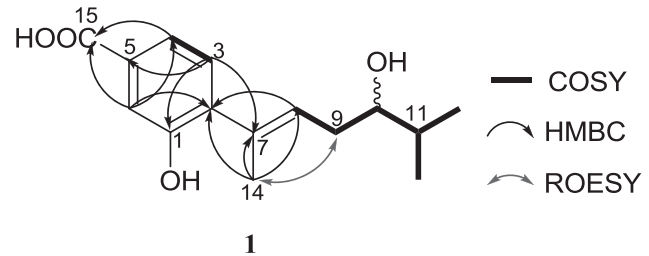

Figure 2 The key ${ }^{1} \mathrm{H}^{1}{ }^{1} \mathrm{H}$ COSY, HMBC and ROESY correlations of 1 . A full color version of this figure is available at The Journal of Antibiotics journal online.

on an Applied Biosystems Mariner 5140 spectrometer. TLC and column chromatography were performed on plates precoated with silica gel $\mathrm{GF}_{254}$ $(10-40 \mu \mathrm{m})$ and over silica gel (200-300 mesh; Qingdao Marine Chemical Factory, Qingdao, China), and Sephadex LH-20 (Amersham Biosciences, Uppsala, Sweden), respectively. All solvents used were of analytical grade (Tianjin Fuyu Chemical and Industry Factory, Tianjin, China). Semipreparative HPLC was performed using an ODS column (YMC-pack ODS-A, Kyoto, Japan, $10 \times 250 \mathrm{~mm}, 5 \mu \mathrm{M}, 4 \mathrm{ml} \mathrm{min}^{-1}$ ).

\section{Fungal strain}

A. sydowii ZSDS1-F6 was isolated from an unidentified sponge, which was collected from the Xisha Islands of China in 2012 , and stored at $-20^{\circ} \mathrm{C}$. The frozen sample was defrosted in sterile distilled water and washed with sterile distilled water. The washed sample $(1 \mathrm{~g})$ was ground with sterile distilled water $(10 \mathrm{ml})$ and then was diluted to $10^{-3} \mathrm{~g} \mathrm{ml}^{-1}, 100 \mu \mathrm{l}$ of which was dispersed across a solid-phase agar plate (Czapek's media) and incubated at $28^{\circ} \mathrm{C}$ for 7 days. On the marginal zone, blue-green colonies were observed with white edges. A single colony was transferred onto Czapek's media. It was identified according to its morphological characteristics and ITS gene sequences (GenBank accession no. KF408294). A reference culture is deposited at our laboratory at $-80{ }^{\circ} \mathrm{C}$. The producing strain was prepared on potato dextrose agar slants at $3.3 \%$ salt concentration and stored at $4{ }^{\circ} \mathrm{C}$.

\section{Fermentation and extraction}

A. sydowii ZSDS1-F6 was incubated on a rotary shaker (180 r.p.m.) at $28^{\circ} \mathrm{C}$ for 7 days in $500 \mathrm{ml} \times 400$ conical flasks containing the liquid medium $(150 \mathrm{ml}$ per flask) composed of starch soluble $\left(10 \mathrm{gl}^{-1}\right)$ and polypeptone $\left(1 \mathrm{gl}^{-1}\right)$, and tap water after adjusting its $\mathrm{pH}$ to 7.5 . The fermented whole broth (60 liters) was filtered through cheesecloth to separate it into filtrate and mycelia. The filtrate was concentrated under vacuum to about a quarter of original volume and then extracted three times with EtOAc to give an EtOAc solution, while the mycelia were extracted three times with acetone. The acetone solution was evaporated under reduced pressure to afford an aqueous solution. The aqueous 
Table $1{ }^{1} \mathrm{H}$ and ${ }^{13} \mathrm{C}$ NMR data of 1 (500 and $125 \mathrm{MHz}, \mathrm{CD} 30 \mathrm{D}, \delta$ in p.p.m.)

1

\begin{tabular}{|c|c|c|c|c|c|}
\hline Position & $\delta_{C}$ mult & $\delta_{H}(J$ in $H z)$ & $\cos Y$ & $H M B C(H \rightarrow C)$ & NOESY \\
\hline 1 & 155.3, C & & & & \\
\hline 2 & $139.1, \mathrm{C}$ & & & & \\
\hline 3 & $130.4, \mathrm{CH}$ & $7.16, \mathrm{~d}(8.0)$ & 4 & $1,5,7$ & 4,8 \\
\hline 4 & $122.1, \mathrm{CH}$ & $7.46, \mathrm{~d}(8.0)$ & 3 & $2,6,15$ & 3 \\
\hline 5 & $132.3, \mathrm{C}$ & & & & \\
\hline 6 & 117.6, CH & $7.44, \mathrm{~s}$ & & $1,2,4,15$ & \\
\hline 7 & $136.7, \mathrm{C}$ & & & & \\
\hline 8 & $128.8, \mathrm{CH}$ & $5.63, \operatorname{td}(7.0,1.2)$ & 9,14 & 2,14 & $3,9,10$ \\
\hline 9 & $34.3, \mathrm{CH}_{2}$ & $2.42, \mathrm{dd}(6.7,4.8) ; 2.33$, q (7.4) & 8,10 & $7,8,10,11$ & $8,10,14$ \\
\hline 10 & $77.5, \mathrm{CH}$ & 3.47 , dt $(8.1,4.9)$ & 9,11 & $8,12,13$ & $8,9,11,12,13$ \\
\hline 11 & $34.5, \mathrm{CH}$ & $1.75, \mathrm{~m}$ & $10,12,13$ & $10,12,13$ & $10,12,13$ \\
\hline 12 & $19.5, \mathrm{CH}_{3}$ & $0.9942, d(6.8)$ & 11 & $10,11,13$ & $10,11,13$ \\
\hline 13 & $17.9, \mathrm{CH}_{3}$ & $0.9918, d(6.7)$ & 11 & $10,11,12$ & $10,11,12$ \\
\hline 14 & $17.2, \mathrm{CH}_{3}$ & $2.03, \mathrm{~s}$ & & $2,7,8$ & 9 \\
\hline 15 & $170.9, \mathrm{C}$ & & & & \\
\hline
\end{tabular}

solution was extracted three times with EtOAc to give another EtOAc solution. Both EtOAc solutions were combined and concentrated under vacuum to give an EtOAc extract $(19.5 \mathrm{~g})$.

\section{Purification}

The EtOAc extract $(19.5 \mathrm{~g})$ was subjected to VLC on a silica-gel column using step-gradient elution with $\mathrm{MeOH} / \mathrm{CH}_{2} \mathrm{Cl}_{2}(0-100 \%)$ to separate into eight fractions based on TLC properties. Fraction $4(1.1 \mathrm{~g})$ was divided into five parts (Frs. 4-1-4-5) followed by Sephadex LH-20 (MeOH). Fr. 4-3 $(115 \mathrm{mg})$ was directly separated by HPLC $\left(80 \% \mathrm{MeOH} / \mathrm{H}_{2} \mathrm{O}\right)$ to yield 2 (3.2 mg, $\left.t_{\mathrm{R}} 24.7 \mathrm{~min}\right), 3\left(5.4 \mathrm{mg}, t_{\mathrm{R}} 26.3 \mathrm{~min}\right)$ and $4\left(3.8 \mathrm{mg}, t_{\mathrm{R}} 22.4 \mathrm{~min}\right)$, respectively. Fr. 4-3-1 (14 mg) was purified by Sephadex $\mathrm{LH}-20\left(\mathrm{CH}_{2} \mathrm{Cl}_{2} /\right.$ $\mathrm{MeOH}, 1: 1)$ to yield $5(1.3 \mathrm{mg})$ and $\mathbf{6}(1.1 \mathrm{mg})$. Fr. $5(320 \mathrm{mg})$ was purified by Sephadex LH-20 $\left(\mathrm{CH}_{2} \mathrm{Cl}_{2} / \mathrm{MeOH}, 1: 1\right)$ followed by HPLC $\left(60 \% \mathrm{MeOH} / \mathrm{H}_{2} \mathrm{O}\right)$ to yield $10\left(47.1 \mathrm{mg}, t_{\mathrm{R}} 24.3 \mathrm{~min}\right)$. Fraction $6(2.8 \mathrm{~g})$ was divided into four parts (Frs. 6-1-6-4) by Sephadex LH-20 (MeOH). Fr. 6-3 (1.6g) was further purified by Sephadex LH-20 (MeOH) to separate into two fractions (Frs. 6-3-1 and 6-3-2). Compounds 1 ( $\left.3.7 \mathrm{mg}, t_{\mathrm{R}} 21.0 \mathrm{~min}\right), 7$ (993 mg, $\left.t_{\mathrm{R}} 29.3 \mathrm{~min}\right), 8$ $\left(4.7 \mathrm{mg}, t_{\mathrm{R}} 23.1 \mathrm{~min}\right)$ and $9\left(7.3 \mathrm{mg}, t_{\mathrm{R}} 16.8 \mathrm{~min}\right)$ were obtained from Fr. 6-3-1 $(1.3 \mathrm{~g})$ by semipreparative HPLC eluting with $68 \% \mathrm{MeOH}$. Similarly, compounds 11 (11.3 mg, $\left.t_{\mathrm{R}} 13.3 \mathrm{~min}\right)$ and $12 \quad\left(2.4 \mathrm{mg}, t_{\mathrm{R}} \quad 10.5 \mathrm{~min}\right)$ were obtained from Fr. 6-3-2 $(210 \mathrm{mg})$ by semipreparative HPLC eluting with $63 \% \mathrm{MeOH}$.

Aspergillusene C (1): colorless gum; [ $\alpha$ ]25 D-4.1 ( $c$ 0.4, MeOH); UV (MeOH) $\lambda_{\max }(\log \varepsilon) 205$ (3.35), 253 (2.86), 296 (2.66) nm; IR (KBr) $v_{\max } 3375,1686$, $1420,1288,1261,1204,1146,1018 \mathrm{~cm}^{-1} ;{ }^{1} \mathrm{H}$ NMR and 13C NMR data, see Table 1; HRESIMS $m / z 265.1423[\mathrm{M}+\mathrm{H}]^{+}$(calcd for $\mathrm{C}_{15} \mathrm{H}_{21} \mathrm{O}_{4}$, 265.1434).

\section{CONFLICT OF INTEREST}

The authors declare no conflict of interest.

\section{ACKNOWLEDGEMENTS}

This work was supported financially by the National Key Basic Research Program of China (973)'s Project (2010CB833800 and 2011CB915503), the Open Foundation of the Key Lab of Marine Bioactive Substance and Modern Analytical Technique, SOA (MBSMAT-2013-02), the National High Technology Research and Development Program (863 Program, 2013AA092901 and 2012AA092104), the National Natural Science Foundation of China (Nos. 31270402, 21172230, 20902094, 41176148 and 21002110), Guangdong Province-CAS Joint Research Program (2011B090300023 and 2012B091100264) and Guangdong Marine Economic Development and Innovation of Regional Demonstration Project (GD2012-D01-001 and GD2012-D01-002).

1 Morens, D. M., Folkers, G. K. \& Fauci, A. S. The challenge of emerging and re-emerging infectious diseases. Nature 430, 242-249 (2004).

2 Weigel, L. M. et al. High-level vancomycin-resistant Staphylococcus aureus isolates associated with a polymicrobial biofilm. Antimicrob. Agents Chemother. 51, 231-238 (2007).

3 Blunt, J. W., Copp, B. R., Keyzers, R. A., Munro, M. H. G. \& Prinsep, M. R. Marine natural products. Nat. Prod. Rep. 29, 144-222 (2013).

4 Saleem, M. et al. Marine natural products of fungal origin. Nat. Prod. Rep. 24, 1142-1152 (2007).

5 Zhu, W. M. \& Wang, J. F. A review on studies of secondary metabolites from marine fungi. Mycosystema 30, 218-228 (2011).

6 Zhuravleva, O. I. et al. Secondary metabolites from a marine-derived fungus Aspergillus carneus Blochwitz. Phytochemistry 80, 123-131 (2012).

7 Scherlach, K., Schuemann, J., Dahse, H. M. \& Hertweck, C. Aspernidine A and B, prenylated isoindolinone alkaloids from the model fungus Aspergillus nidulans. J. Antibiot. 63, 375-377 (2010).

8 Takagi, M., Motohashi, K. \& Shin-ya, K. Isolation of 2 new metabolites, JBIR-74 and JBIR75, from the sponge-derived Aspergillus sp. fS14. J. Antibiot. 63, 393-395 (2010).

9 Chung, Y. M. et al. An epigenetic modifier enhances the production of anti-diabetic and anti-inflammatory sesquiterpenoids from Aspergillus sydowii. Bioorg. Med. Chem. 21, 3866-3872 (2013).

$10 \mathrm{He}, \mathrm{F}$. et al. Indole alkaloids from marine-derived fungus Aspergillus sydowii SCSIO 00305. J. Antibiot. 65, 109-111 (2012).

11 Trisuwan, K. et al. Sesquiterpene and xanthone derivatives from the sea fan-derived fungus Aspergillus sydowii PSU-F154. J. Nat. Prod. 74, 1663-1667 (2011).

12 Ren, H. et al. Two new hetero-spirocyclic $\gamma$-lactam derivatives from marine sedimentderived fungus Aspergillus sydowi D2-6. Arch. Pharm. Res. 33, 499-502 (2010).

$13 \mathrm{Li}$, D. et al. Antibacterial bisabolane-type sesquiterpenoids from the sponge-derived fungus Aspergillus sp. Mar. Drugs 10, 234-241 (2012).

14 Henne, P. et al. Waraterpols, new penicillium metabolites and their derivatives. Liebigs Ann. Chem. 5, 565-571 (1993).

15 Kudo, S. et al. Isolation and absolute stereochemistry of optically active sydonic acid from Glonium sp. (Hysterriales, Ascomycota). Biosci. Biotechnol. Biochem. 73, 203-204 (2009).

$16 \mathrm{Lu}$, Z. Y. et al. Cytotoxic polyphenols from the marine-derived fungus Penicillium expansum. J. Nat. Prod. 73, 911-914 (2010).

17 Fremlin, L. J., Piggott, A. M., Lacey, E. \& Capon, R. J. Cottoquinazoline A and cotteslosins $\mathrm{A}$ and $\mathrm{B}$, metabolites from an Australian marine-derived strain of Aspergillus versicolor. J. Nat. Prod. 72, 666-670 (2009).

18 Bunyapaiboonsri, T., Yoiprommarat, S., Intereya, K. \& Kocharin, K. New diphenyl ethers from the insect pathogenic fungus Cordyceps sp. BCC 1861. Chem. Pharm. Bull 55, 304-307 (2007).

19 Kimura, Y. et al. Cyclo-(L-tryptophyl-L-phenylalanyl), a plant growth regulator produced by the fungus Penicillium sp. Phytochemistry 41, 665-669 (1996).

Supplementary Information accompanies the paper on The Journal of Antibiotics website (http://www.nature.com/ja) 